\title{
Derechos fundamentales y relaciones de empleo
}

\author{
Adrián Calderón Chacón \\ Magister en Derecho del Trabajo y Seguridad Social de la UNED \\ Doctorando en Derecho de la UNED \\ Juez de Trabajo del Segundo Circuito Judicial de San José \\ Correo Electrónico: adriancalderonch@gmail.com
}

Recibido: Enero 2015 • Aceptado: Febrero 2015

\section{RESUMEN}

La aplicación de los derechos fundamentales a las relaciones de trabajo conlleva una nueva visión del Derecho Laboral, según la cual se busca ubicar a la persona trabajadora en una posición de preferencia en la que sus garantías básicas o elementales que emanan del texto de la Constitución, se convierten en una protección reforzada contra el ejercicio de las potestades del empresario.

Palabras claves: derechos fundamentales, garantías constitucionales, contrato de trabajo, eficacia horizontal.

\begin{abstract}
The application of fundamental rights to labor relations entails a new vision of Labor Law, that seeks to privilege employees with the granting of elementary Constitutional guarantees, reinforcing protection against power executed by the employers.
\end{abstract}

Keywords: fundamental rights, constitutional rights, employment contract, horizontal effect.

\section{Introducción}

En el presente documento se propone realizar un análisis acerca de la vinculación existente entre los derechos fundamentales inespecíficos y específicos recogidos en la Carta Magna y las relaciones de trabajo. Con ese fin se procederá a plasmar una caracterización de esta figura jurídica a través de la doctrina, normas jurídicas y en la jurisprudencia nacional más relevante sobre el tema.

Como primer aspecto de estudio se elaborará una reseña histórica sobre el proceso de inclusión de las garantías laborales en los diversos textos constitucionales $\mathrm{y}$, de manera posterior, se desarrollará una reseña sobre el cambio de visión que ha operado acerca de su carácter normativo en las relaciones entre privados.

\section{Los Derechos Fundamentales y su ámbito aplicación en el ordenamiento jurídico laboral costarricense}

Los diversos instrumentos internacionales desarrollan una serie de valores y postulados que constituyen derechos inherentes a la condición de ser humano, los cuales sustentan el acceso a una serie de garantías esenciales que fijan condiciones mínimas para el desarrollo de la persona de forma digna. Esta clase de enunciados 
denominados "derechos humanos" han sido positivizados dentro de las constituciones políticas de los Estados, dando origen a los denominados derechos fundamentales.

El paso histórico que se reseña expresa el interés del constituyente de dotar de protección específica a la persona, haciendo oponible frente al Estado y ante terceros esta clase de derechos, dotando de tal forma a la persona de un ámbito de libertad, lejos de la injerencia de otros. El autor argentino Rodríguez (2007) define a esta clase de normas de la siguiente manera:

\begin{abstract}
"Bajo la denominación de -derechos fundamentales (DF), la doctrina y la legislación se refieren a ciertos derechos que, por su trascendencia, su jerarquía en el conjunto de los que son atribuidos a la persona humana, constituyen un núcleo central, esencial, que debe ser protegido de manera especial y fuerte frente a los eventuales ataques provenientes, sobre todo, del Estado” (Rodríguez, 2007: 1).
\end{abstract}

Los derechos fundamentales, por su naturaleza representan un eje transversal que nutre todas las ramas del ordenamiento jurídico. Estos no solamente cumplen con la función de garantizar un núcleo esencial de libertad de autodeterminación, sino que son obligaciones coactivas para el Estado, el cual debe fomentar la creación de un entorno adecuado para la consolidación de esos derechos subjetivos. Dichas garantías no sólo son oponibles frente a la Administración, sino que se tornan efectivas respecto a aquellas relaciones jurídicas que nacen entre sujetos regidos por el derecho privado, lo que implica la denominada eficacia pluridimensional de los mismos.

Esta última aplicación de los derechos fundamentales, según explica Pedrajas (1992), se debe a un proceso histórico nacido en la Alemania Federal en el período de la postguerra, donde se disponía de una eficacia inmediata de los derechos fundamentales entre particulares. Sin embargo, esta teoría no ha sido desde sus inicios de una aceptación irrestricta. Así, en palabras del autor:

"La tesis de la Drittwirkung, que sostiene la eficacia frente a terceros de la derechos fundamentales, fue elaborada por Hans Carl Nipperdey y aceptada por el Tribunal Federal de la República Federal Alemana en 1954. Si, inicialmente, los tribunales alemanes acogieron admitiendo la eficacia inmediata de los derechos fundamentales entre particulares, es decir, que dichos derechos rigen y son aplicación directa en las relaciones privadas, sin embargo, algún tiempo más tarde, la posición jurisdiccional derivó hacia la admisión únicamente de una eficacia mediata de dichos derechos, lo que vendría a implicar que lo que sería susceptible de someter a enjuiciamiento serían los actos de los poderes públicos configuradores de las situaciones jurídico-privadas conforme a los derechos fundamentales. Así, pues, si la admisión de la eficacia inmediata de la Drittwirkung conllevaba una correlativa aceptación posterior, reconociendo sólo la eficacia mediata, supuso el acogimiento de una vía intermedia, que se enlaza, de forma clara, con la tesis admitida entre nosotros de la imputación a los órgano jurisdiccionales de la violación de derechos fundamentales por omisión o deficiente protección de los mismos." (Pedrajas Moreno, 1992: 28).

Esta peculiaridad, a criterio de Valdés (2003), se debe a que las relaciones entre privados han evolucionado de tal manera hasta conformar verdaderos centros de poder privado, en los cuales se expone al ciudadano a peligros. Por lo tanto, se vuelve imprescindible su tutela:

"Los duros hechos de la historia ya se han encarga-
do de levantar el velo de su inconsistencia política y
jurídica; de demostrar que la igualdad no es princi-
pio que acompañe a la libertad contractual; que lo
público y lo privado no forman zonas recíprocamen-
te estancas sino, antes al contrario áreas mestizas,
de cruce y encuentro e, incluso, intercambiables a
veces (privatización del poder público y publifica-
ción del poder privado); que la supremacía priva-
da asume muy a menudo una relevancia social, que
crea situaciones inter privados de tanta o de mayor
sujeción que la que se da en la relación pública; que
la existencia de verdaderos centros de poder priva-
do, dotados de vigorosas potestates agendi, hace ya
tiempo que ha dado al traste con la idílica visión
de un sistema de relaciones competitivas dominadas
por la par libertadligualdad. En definitiva, el poder
público ha perdido la credencial de ser el único ene-
migo de la libertades fundamentales, compartiendo
ahora esta condición con otros poderes, económicos 
y sociales, que en muchas ocasiones son más implacables que el propio Estado en la violación de los derechos fundamentales." (Valdés, 2003)

Este proceso de oposición de los derechos fundamentales frente a sujetos privados se sitúa necesariamente en el ámbito del derecho del trabajo. Valdés (2003) reitera que la eficacia pluridimensional de los derechos fundamentales encuentra un modo de expresión muy marcado en las relaciones laborales. En estas hipótesis las asimetrías de poder se tornan incuestionables y debe existir una tutela del Estado, en procura de equilibrar dicho desequilibrio social:

(...) centrando la atención en esta última transformación y retornando al argumento apenas esbozado, no me parece arriesgado afirmar que la doctrina de la Drittwirkung der Grundrecht, de la eficacia pluridireccional de esos derechos, ha madurado y se ha desarrollado, en buena parte, al calor del principio iusrealismo contractual que impregna todas las secuencias vitales de la relación laboral: la radical asimetría de poder entre empresario y trabajador, y que se expresa, desde luego, en las distintas posiciones jurídicas que cada uno ocupa en la relación laboral, pero también, y con no menor significación, en el más amplio espacio de la vida social y económica. (Valdés, 2003)

La incidencia de este tipo de tutela representa el reconocimiento de parte de los ordenamientos jurídicos de situaciones de inequidad que deben ser reguladas con el fin de cumplir el objetivo supremo de la vida en sociedad, el cual es sin duda alguna el bien común. De esta forma, las diversas constituciones han optado por establecer normas, que posteriormente se han desarrollado por la legislación ordinaria, las que han servido para disponer jurídicamente de mecanismos esenciales para garantizar la dignidad de la persona y la correcta distribución de la riqueza; aspectos insoslayables desde el punto de vista del derecho laboral consagrado en la Carta Magna costarricense. Expone Baylos (2003):

El compromiso de los poderes públicos por promover las condiciones para que la libertad y la igualdad formalmente reconocidas a los individuos sean reales y efectivas, que lleven aparejado la remoción de los obstáculos que impidan o dificulten su plenitud (art. 9 CE), significa en todo caso el reconocimiento de una situación de desigualdad económica y social como elemento constitutivo de las sociedades actuales y el simultáneo compromiso por parte del Estado de actuar en el sentido de una gradual y progresiva nivelación social de estas asimetrías económicas, sociales y culturales. A este esfuerzo nivelador son funcionales los derechos sociales reconocidos constitucionalmente -clásicamente los derechos prestacionales a cargo del Estado y la atribución de relevancia constitucional a las formaciones sociales que expresan el interés del sujeto colectivo desigual que se localiza en la esfera de la producción y de la distribución: los trabajadores como clase social subalterna. (Baylos, 2003: 17-18)

Palomeque y Álvarez (2002) señalan la existencia de un denominado "bloque de laboralidad" dentro de las normas fundamentales de los Estados, rescatando un proceso de construcción de los derechos laborales, a partir de la Constitución Mexicana de Querétaro en 1917. Para ellos, es ahí en donde se da el inicio de la introducción de esta clase de máximas dentro del ordenamiento constitucional, proceso que posteriormente fue extendiéndose a los restantes Estados Sociales de Derecho. Concretamente refieren:

El proceso de constitucionalización de los derechos sociales de la persona o el acceso de estas situaciones jurídicas a la norma constitucional, dentro de los que se encuentran de modo principal los derivados de las relaciones laborales, se producía, por su parte, dentro del primer cuarto del siglo $X X$, de la mano de la construcción de la categoría de Estado Social de Derecho. Así, por vez primera en la historia, la Constitución mexicana de Querétaro (1917) contiene, no sólo principios generales, sino normas jurídicas sobre salario, jornadas, libertad de sindicación o derecho de huelga. Será, sin embargo, la Constitución alemana de Weimar (1919) quién proporcione el modelo o paradigma constitucional para los textos europeos y americanos de la postguerra mundial, en que el trabajo es objeto de singular consideración como factor esencial de la vida económica y política, recogiéndose nuevos compromisos estatales en materia de protección especial de la mano de obra, establecimiento de un 
Derecho obrero uniforme, garantía de la libertad de asociación profesional para la defensa y mejora de las condiciones económicas y laborales, adopción de una politica de seguros sociales, apoyo a la legislación internacional del trabajo, participación de los trabajadores en la administración de las empresas, o proclamación de los derechos al trabajo y el descanso en el trabajo. (Palomeque \& Alvarez, 2002: 134-135)

Dichos autores consideran al derecho de la Constitución como fuente primaria y esencial para el derecho de trabajo. De esta manera se asientan las bases, para que, de manera posterior, ingresen a escena otras fuentes de regulación, las cuales emanan su poder social precisamente del texto de la Constitución, tal es el caso de las normas de origen autónomo.

Asimismo, dichos autores plantean el tema de los derechos específicos e inespecíficos. A su vez, deslindan, aquellas garantías constitucionales endémicas de la disciplina laboral y aquellas otras que son consustanciales a la condición del ser humano:

Al propio tiempo, otros derechos constitucionales de carácter general y, por ello, no específicamente laborales pueden ser ejercidos, sin embargo, por los sujetos de las relaciones de trabajo (los trabajadores, en particular) en el ámbito de las mismas, por lo que en tal caso adquieren un contenido o dimensión labores sobrevenidos. Se produce así una impregnación laboral de derechos de titularidad general o inespecífica por el hecho de su ejercicio por trabajadores asalariados (también eventualmente por empresarios) a propósito y en el ámbito de un contrato de trabajo. Son derechos atribuidos con carácter general a los ciudadanos, que son ejercidos en el seno de una relación jurídica laboral por ciudadanos que, al propio tiempo, son trabajadores y, por lo tanto, se convierten en verdaderos derechos laborales por razón del sujeto y de la naturaleza de la relación jurídica en que se hacen valer, en derechos constitucionales laborales inespecificos. (Palomeque y Álvarez, 2002: 149-150)

Este fenómeno de introducción de derechos laborales en los textos constitucionales no es ajeno del ordenamiento jurídico costarricense.
Respecto al mismo, la Constitución Política, en su Título V, ha incorporado una serie de normas de carácter social, verdaderos derechos públicos subjetivos, instituyendo como derechos fundamentales el acceso al trabajo digno, la existencia de un salario mínimo, limitación de la jornada de trabajo, día de descanso, libre sindicación, negociación colectiva, huelga, paro y formación profesional. Con ello, se presupone un núcleo esencial de protección de la persona trabajadora, el cual se ha visto traducido en regulaciones heterónomas donde estos preceptos son desarrollados.

Martin (1998) denomina este suceso como la "constitucionalización" del ordenamiento laboral, lo que a su juicio ha implicado una restructuración del sistema jurídico. Esto ha permeado todas las esferas de interés del derecho de trabajo, trayendo consigo otros cauces para el desarrollo de las relaciones obrero-patronales, lo que desde su punto de vista conlleva nuevas interpretaciones de las normas jurídicas y aplicación de las mismas a distintos escenarios:

La constitucionalización del ordenamiento laboral ha significado, así una profunda reestructuración de las distintas piezas normativas que lo componen. En verdad, muchas de ellas son nuevas, habiendo correspondido su elaboración al legislador. También es cierto que algunas de estas piezas (no muchas en el Derecho individual del trabajo o Derecho del contrato de trabajo) han desaparecido al haberse comprobado su incompatibilidad con la norma fundamental. (...). Por decirlo de alguna manera, la Constitución ha creado un nuevo campo magnético en el ordenamiento laboral, y su fuerza de atracción sobre los elementos o componentes de éste se ha dejado sentir con más o menos intensidad de todas las parcelas del Derecho de Trabajo. (Martin Valverde, 1998: IX-XXIV)

Según se ha mencionado anteriormente, las relaciones laborales y los derechos fundamentales se encuentran ligados. En la práctica esta interrelación comporta un límite para las actuaciones del empleador, el cual en su actuar debe respetar ese cúmulo básico de libertades y garantías que posee el trabajador. 
La Organización Internacional del Trabajo (OIT) emitió el documento denominado "Declaración Relativa a los Principios y Derechos Fundamentales en el Trabajo". En esa declaración se conciben cuatro áreas de protección: libertad sindical, trabajo forzoso $\mathrm{u}$ obligatorio, trabajo infantil y discriminación en materia de empleo y ocupación. Resulta de imperiosa necesidad traer a colación el texto del artículo $2^{\circ}$ de ese cuerpo normativo en cuanto en él se afirma lo siguiente:

Declara que todos los Miembros, aun cuando no hayan ratificado los convenios aludidos, tienen un compromiso que se deriva de su mera pertenencia a la Organización de respetar, promover y hacer realidad, de buena fe y de conformidad con la Constitución, los principios relativos a los derechos fundamentales que son objeto de esos convenios, es decir:

a) la libertad de asociación y la libertad sindical y el reconocimiento efectivo del derecho de negociación colectiva;

b) la eliminación de todas las formas de trabajo forzoso u obligatorio;

c) la abolición efectiva del trabajo infantil; y

d) la eliminación de la discriminación en materia de empleo y ocupación.

Esta visión de las relaciones laborales, supone la inclusión de los derechos fundamentales como una frontera para el ejercicio del poder del empleador, quien en todo momento debe mirar como límite de su propia actuación la dignidad del trabajador. Explica Rodríguez (2007):

(...) la aplicación de los DF a las relaciones privadas supone un paso importante en el reconocimiento de la profundidad que poseen, a partir de la constatación de que el ingreso del trabajador - persona humana-al ámbito de una relación contractual voluntaria, supone justamente un recorte a su autonomía de la voluntad, consistente en la opción-más o menos libremente adoptada-de someterse a las órdenes e instrucciones de otro sujeto. Pero subrayando que tal sometimiento no significa marginarlo de las normas generales que reconocen los DF a-todos los habitantes. (Rodríguez, 2007: 102)

De igual manera, la Sala Segunda de la Corte Suprema de Justicia en el voto 2010-0124 de las 10:00 horas del 22 de enero de 2010, resaltó la importancia primordial de los derechos fundamentales en la regulación del contrato individual de trabajo. Así, sobre el tema afirmó:

Correlativamente los derechos fundamentales recogidos en las normas constitucionales, mediante el proceso de eficacia horizontal han servido para desarrollar un nuevo paradigma de las relaciones laborales. A raiz de ese modelo de derecho constitucional-laboral, se ha dado respuesta a un serie de situaciones que comprometían los derechos fundamentales del trabajador, mismas que [antaño] eran legitimadas en el poder de control y dirección del empleador. Ejemplo de ello en nuestro ordenamiento jurídico es la tutela ideada para personas objeto de despidos discriminatorios operados por razones de género, orientación sexual y creencias religiosas, tesis que han sido derivadas mayormente del principio de igualdad, consagrado por el precepto 33 de la Constitución Politica. En este orden de ideas, el derecho de intimidad de la persona trabajadora emanado del ordinal 24 constitucional, se sitúa como un óbice para el ejercicio del poder del empresario, es decir, sirve para imposibilitar que se realicen controles de la vida personal del trabajador que estén disociados de la prestación personal pactada. El derecho de intimidad constriñe al empleador a abstenerse de investigar aspectos de la personalidad del trabajador tales como su orientación sexual, modo de vida, militancia política y prácticas religiosas, puesto que estos en modo alguno condicionan la capacidad profesional, fisica e intelectual para el ejercicio de las laborares remuneradas. Por esa razón, el control de la esfera privada del trabajador, únicamente será válida en la hipótesis que el comportamiento extralaboral sea contradictorio con las labores debidas, campo en el que se debe incluir el control de sustancias psicotrópicas. (Sala Segunda 2010-0124)

Partiendo de una argumentación como la presente, en la cual se acepta la simbiosis entre las garantías constitucionales de la persona y las relaciones laborales, parece obvia la clara conexión entre el tema constitucional y el derecho de 
trabajo. No obstante, esta relación es un espacio de discusión limitado, sobre todo porque en muchos casos los poderes de control y dirección del patrono son una fuente de legitimación del desconocimiento sistemático de estos derechos.

Respecto a este punto resulta válido realizar una severa crítica sobre el presunto principio de libre despido elucubrado por la jurisprudencia costarricense. En este, se observa que tribunales costarricenses, ante la colisión de los derechos de libertad de empresa y estabilidad en el empleo, sin mayores razones se ha decantado por tutelar la posición de supremacía de la organización empresarial.

En otro orden de ideas, Valdés (2004) expone que la oposición de los derechos fundamentales se convierte en un blindaje para el trabajador ante los constantes ataques provenientes de la posición hegemónica del empresario:

De seguro, la relación jurídica obligatoria nacida del contrato de trabajo constituye el banco de prueba de la eficacia horizontal de los derechos fundamentales de carácter personalísimo, entendida esa expresión, la de banco de pruebas, en un doble sentido experimental y teórico. La difícil convivencia de las libertades del trabajador en el marco del contrato de trabajo se debe a una constelación de causas de variada naturaleza. (...). La noción normativa de la figura del trabajador, normalmente definida en la práctica totalidad de los ordenamientos positivos como aquella parte de una relación contractual que, a cambio de un salario, se compromete a realizar un trabajo por cuenta y bajo la subordinación de otra, denominada empleador o empresario, ya instituye unas posiciones jurídicas activas y pasivas, de desigualdad contractual. La subordinación o dependencia, presupuesto constitutivo de la existencia del vínculo jurídico, confiere al empresario unos poderes que, aun cuando tiene un carácter instrumental de garantía de cumplimiento, por el trabajador, de la prestación laboral debida, inciden en la esfera personal de trabajador, comprometiendo una parte de su agere libre. A ella se añade el dato, de no menor significación, de que habitualmente el trabajador ejecuta su trabajo en el marco de una organización de empresa cuyo funcionamiento, pensado para la satisfacción de los intereses empresariales, acentúa los poderes del empresario a los que el trabajador se subordina. / El trabajador lleva así a la relación laboral unos derechos, los inherentes a su persona, que son previos al contrato que concierta y de superior rango y valor a los que en él puedan haberse acordado, pero cuyo ejercicio va a repercutir ineludiblemente en el propio contrato y en la organización de empresa en la que éste se inserta, instituciones estás, la contractual y la empresarial, que responden a unas lógicas inicialmente poco favorables para esas pretensiones. La idea puede ser expresada menos abstracta, con referencia a uno de los poderes típicos del empresario; el poder de dirección. En su función ordenadora de la prestación laboral, el poder de dirección es un instrumento especialmente apropiado para por acción y omisión, desconocer o lesionar los derechos de la persona del trabajador. En la medida, en efecto, en que este poder, de contornos difusos y dotados de una acentuada legitimidad, tiene a su disposición de manera permanente el argumento organizativo, puede instalarse un ambiente claramente adverso a aquellos derechos. (Valdés, 2004: 88-89)

La idea del ejercicio armónico de los derechos fundamentales de la persona trabajadora y la libertad de empresa del empleador, en el caso de Costa Rica no ha sido aceptada en términos amplios, sobre todo en el ámbito de los derechos laborales colectivos. Esta particular patología se observa con gran intensidad, si observamos que además de existir una escasa regulación sobre el tema, hay presente una gran reticencia a nivel empresarial respecto de permitir el libre ejercicio de esa libertad. Sin embargo, a nivel del contrato individual de trabajo se aprecian interesantes avances en lo relacionado a los fueros de protección, ejercicio de libertades individuales y la aceptación a nivel jurisprudencial de un amplio esquema de reparaciones y resarcimientos ante la violación de estas garantías esenciales.

\section{Conclusiones}

La clara relación desarrollada entre garantías fundamentales y relaciones laborales permite afirmar que a partir del reconocimiento de los derechos fundamentales en las relaciones de trabajo se ha dado una verdadera reformulación de los conceptos y postulados sobre los que por 
muchos años había descansado el derecho del trabajo costarricense.

Con la aplicación de las garantías específicas e inespecíficas dispuestas por la Constitución Política al contrato individual de trabajo se ha logrado dar respuestas a situaciones de violencia, discriminación y abuso, que desde larga data encontraban su justificación en los poderes señoriales que el ordenamiento jurídico dispone para el empresario. Los mecanismos de control y dirección y las restantes potestades del empleador cuentan con un nuevo límite infranqueable, expresado en la dignidad de la persona trabajadora.

Desde el punto histórico, resulta sumamente interesante la compleja elaboración que ha tenido el discurso de los derechos fundamentales en las relaciones entre sujetos de derecho privado. La visión que en la actualidad mantiene la Sala Segunda sobre el tema debe subrayarse como un avance de una inmensa importancia, que sitúa a la jurisdicción laboral costarricense como un mecanismo efectivo de defensa de la supremacía constitucional.

A pesar de lo anterior, es lamentable la ponderación que se ha brindado a la libertad de empresa sobre el principio de estabilidad empleo. Dicha situación se ve empeorada, si se advierte que existe carencia de una legislación de fondo en tópicos tan sensibles como el despido colectivo por razones económicas y de empresa.

Siempre que exista una colisión de derechos, el juicio de ponderación normativa deberá inclinarse ante la parte más débil y vulnerable del vínculo obligacional, de ahí que la solución a este tema ha de reconsiderarse para encontrar un punto medio.

\section{Referencias Bibliográficas}

Baylos, Antonio. (2003). El derecho al trabajo como derecho constitucional. En C. G. Judicial, La protección de derechos fundamentales en el orden social (págs. 15-53). Madrid: Lerko Print S.A.

Martin, Antonio. (1998). Prólogo. En Fernando. Lousada Arochena y Matias Movilla García, Derechos Fundamentales y Contrato de Trabajo (págs. IX- XXIV). Granada: Comares.

Palomeque z, Manuel Carlos y Álvarez, Manuel. (2002). Derecho del Trabajo. Madrid: Editorial centro de estudios Ramón Areces S.A.

Pedrajas, Abdón. (1992). Despido y derechos fundamentales. Estudio especial de la presunción de inocencia. Madrid: Trotta.

Rodríguez, Jorge. (2007). Derechos Fundamentales y Relaciones Laborales. Buenos Aires: Astrea.

Costa Rica, Sala Segunda de la Corte Suprema de Justicia. Voto 2010-0124 de las 10:00 horas del 22 de enero de 2010.

Valdés, Fernando. (2004). Los derechos fundamentales de la persona del trabajador. En A. U. Social, Libro de Informes Generales XVII Congreso Mundial de Derecho del Trabajo y de la Seguridad Social. Montevideo, Uruguay: Sociedad Internacional de Derecho del Trabajo y de la Seguridad Social.

VALdÉs, Fernando. (2003). La Vinculabilidad Jurídica de los Derechos Fundamentales de la Persona del Trabajador. Recuperado el 7 de setiembre de 2009, de http://dialnet. unirioja.es/servlet/articulo?codigo $=835590$ 
